\title{
Trees and temperature
}

When reconstructing temperature patterns on millennial scales, one key technique scientists have turned to is measuring the width of tree rings; the rings that grow in warmer summers tend to be wider. Such work has typically suggested relatively flat temperatures for the 2,000 or so years before the Industrial Age. But it turns out that a different way of analysing tree rings might give a more accurate view of past temperatures (Nature Clim. Change http:// go.nature.com/lRNUgO; 2012). The study suggests that instead of being flat, temperatures in Northern Europe cooled by about $0.31{ }^{\circ} \mathrm{C}$ per millenium between the Roman era and AD 1900.

Rather than looking at ring width, the team led by Jan Esper at Johannes Gutenberg University, Germany, investigated ring density. Warmer temperatures, they say, have consistent effects on wood cells across the summer growth period, whereas the cell division that determines width is more variable and easily distorted over time. On the down side, density analyses are more labour intensive.

The researchers spent years studying almost 600 trees from Northern Finland and Sweden that had been preserved in cool lake waters for centuries. They created a record dating back about 2,200 years. In contrast to existing ring width studies, ring density analyses revealed a significant cooling trend that could mean Roman and Medieval times were, on average, warmer than today - at least during Northern European summers. Temperature proxies aside from tree ring widths - for instance, analyses of gas bubbles in ice cores - have pointed to a similar cooling trend.
The researchers attribute this trend to changes over time in the Earth's position relative to the Sun, based on correlations in the tree ring density pattern and climate model simulations to determine the climate impacts of known orbital shifts.

The cooling levelled off by the year 1900 as the impacts of human activities surpassed the natural cooling trend, so the results do not change our understanding of the degree to which temperatures have risen over the past century. However, if confirmed and if similar results are found in other parts of the world, the long-term cooling trend would place the global warming of the past decades in more accurate context.

The researchers point out that better understanding of this natural variability will aid understanding of climate change: the natural oscillations are still at work, regardless of the degree to which human activities may be affecting the climate.

Mark Schrope is a freelance writer and editor based in Florida.

\section{The journalist's take}

The Esper team's tree ring study had a number of elements with the potential to attract writers and news editors. Ancient trees at the bottom of a lake that hold clues about our planet's history for thousands of years offer an interesting starting point. And the results have plenty of potential for controversy, as the media storm some years ago over the iconic hockeystick graph - used as an image for past temperature evolution - demonstrated. How warm the temperatures were during the past two millennia determines how unusual current warm temperatures are: the warmer the past, the less remarkable the temperatures of the late twentieth and twenty-first centuries. With a generally sweltering summer underway in the US, the paper's timing was ideal - at least for coverage there.

The paper did get press attention from some traditional science outlets such as New Scientist, but little from the general media such as daily newspapers. Predictably, outlets that are overtly sceptical of climate change showed much more interest. The headline at Newsbusters.org, a conservative US online publication, declared that this single study “Thoroughly Debunks Global
Warming," and questioned whether the media would take notice. They largely didn't, so exploring why not might offer a glimpse of how the media works.

As a starting point, it is important to remember that for a science story to get published in the mainstream media, someone typically has to fight for the necessary space - it is generally not needed to fill a gap. Especially at general outlets, such as newspapers or the evening news, science is viewed with some trepidation, as something that does not attract many readers, or might even repel them. Science news is rarely considered a day-to-day essential.

Thus, if in a given week there has already been any science coverage, news editors may feel that they have had their fill. Few readers will scream for more. The tree ring story, as it happens, lost the science media lottery. The paper was published just a few days after what may prove the biggest science story of the year - the announcement of evidence for the Higgs Boson particle.

Reporters usually get about a week's advance notice of upcoming papers. They were therefore in full Higgs Boson mode when they had the chance to notice the study in Nature Climate Change. Of course, to informed readers, particle physics and climate change research are a world apart, but such distinctions often mean little when publication space is limited.

Numerous other effectively coincidental factors also affect the media course of a science story. Many publications are fortunate to have even one science writer, and if he or she is busy with another project or otherwise unavailable, there is probably no chance of notice for anything but the most sensational science stories. A brief and unscientific survey of science writers revealed that one who handles climate change for the New York Times happened to be out of the country when the tree ring story was published.

There are always a multitude of factors at play determining whether a science story gets media exposure. The most important factor is what else is high on the news - and particularly science news - agenda. Going up against the Higgs Boson, among other issues and impediments, this climate change study never had a chance. Had it been a week or two later, who knows? 